\title{
Social Behaviorist Movement: Non-“Spooky Action at a Distance and Eastern Philosophy"
}

\author{
Steven Gerardi \\ Professor Emeritus for Sociology, New York City College of Technology (CUNY), New York, USA \\ Email: PROFSOCCUNY@Gmail.com
}

How to cite this paper: Gerardi, S. (2020). Social Behaviorist Movement: Non-“Spooky Action at a Distance and Eastern Philosophy". Sociology Mind, 10, 15-18. https://doi.org/10.4236/sm.2020.101002

Received: October 10, 2019

Accepted: December 2, 2019

Published: December 5, 2019

Copyright $\odot 2020$ by author(s) and Scientific Research Publishing Inc. This work is licensed under the Creative Commons Attribution International License (CC BY 4.0).

http://creativecommons.org/licenses/by/4.0/

\begin{abstract}
Consistent with the Social Behaviorist' theories of G.H. Mead and C.H. Cooley are Einstein's Scientific Quantum Entanglement (QE) and Nagarajuna's (Eastern Philosopher) concepts of Sunyata which emphasized the importance of society's affirmation of nature. This effort will suggest that the Social Behaviorist mentioned above (Mead \& Cooley) were profoundly influenced by the concepts of Nagarajuna and Einstein in creating the "Looking Glass Self" and the "Social Self" both theories are both based in the need for society to observe, recognize, and understand the natural and socialphenomenon (Sunyata).
\end{abstract}

\section{Keywords}

Quantum Entanglement, Sunyata, G.H. Mead, C.H. Cooley, Looking Glass Self, Social Self, Me, the I

\section{Context of the Research}

This effort will suggest that during the turn of the 20th century many of the intelligentsia were familiar with the scientific and artistic advances of the time. Indeed, this is significant due to the important nexus between human ideas and their effect on society, technology and science (Gerardi, 2016). The 20th Century witnessed accelerated advancements, especially in science. One such 20th century period man was Einstein (Quantum Theory, ET, 1905) (Gerardi, 2018). This effort will suggest that in formulating QT Einstein was familiar with and influenced by The Buddhist Philosopher Nagarajuna's concept of Sunyata.

Sunyata suggested that all "things" are "EMPTY". "Things" neither exist nor do not exist; neither affirmation nor negation. The affirmation of the independent phenomenon must be first seen/noticed by society. Moreover, Sunyata argues that energy creates, sustains and absorbs every phenomenon. Energy is in- 
visible, inaudible, and intangible. It is permanent and immutable. It has no beginning and no end; it remains changeless even while it takes various forms. We can see, hear and touch the various forms of energy; only when it appears in its various forms, and society notices/recognizes it as a form of energy (everything ultimately converts into energy) (Gerardi, 2016).

Einstein's Quantum Theory argued that energy creates, sustains, and ultimately is the only reality (Sunyata concept affirmation by society). Albert Einstein mathematically established that everything is a form of energy (special-relativity equation says, $\mathrm{E}=\mathrm{mc}^{2}$ (" $\mathrm{E}$ " stands for Energy, " $\mathrm{m}$ " for mass or matter and " $\mathrm{c}$ " is the velocity of light). In this work Einstein explained that light has characteristics of both wave and particles. However, this theory could not be fully complete without first explaining what he called "Spooky Action at a Distance" (later labeled Quantum Entanglement (Bottott, 2019). Indeed, before QE was fully investigated it was believed that subatomic particles interacted froma far, hence the idea of "spooky" (Kuttner \& Bruce, 2011). However, Einstein most likely found it impossible to think irrational, indeed Max Weber in his Principle of Rationality concept argued that irrational thought is based in magical, mystical, non-objective world view. By contrast a rational world image is based on objective orderly and scientific thought (Gerardi, 2012). After extensive scientific study Einstein concluded that the photons become entangled at the same time having the same source. The two particles are linked, hence share the same existence (Bottott, 2019) (again the affirmation of the independent phenomenon noticed by society). Indeed, Einstein's QE phenomenon became real when it was recognized (by he and society) that the two identical particles shared the same existence (the idea of the irrational idea of communicating at the speed or greater than light "spooky action" was solved).

\section{Social Behaviorist and Non-"Spooky Action at a Distance"}

Mead's work entitled (The Mind, Self and Society, 1935) centers around the interplay of the human mind and society. He identified distinctive qualities of self, which included a social entity, shaped by the social interaction; and the individual perception of the social self by society. According to Mead for self to emerge there must be a means by which the individual takes on an objective, impersonal position of self. Language Mead argued is the means by which this impersonal position takes place. The individual hearing/understanding one own's thoughts and utterances leading to the recognition of the independent self (Gerardi, 2010). Moreover, G.H. Mead argued that social Role-playing influenced the development of Self through social interaction. Role-playing places the individual in the role of the social other, whereby the independent individual adopts the social other's definition of the independent self. As the result of the social interaction, self is affirmed (Nagarajuna concept of Sunyata). Although it may have looked like "Spooky Action at a Distance", however Mead concluded that social interaction/society's affirmation of the social self, is the only rational explanation 
for the rise of the social self. Hence, the above social interaction "entangles" the "I" and the "ME". The "I", according to Mead is the unique sense of self, and the "ME" is the social concept of self (Gerardi, 2010). Finally, as the self is realized and recognized through social interaction, the affirmation of the two components self-shares the same existence (the Q.E. Concept) and not the magic of "Spooky Action at a distance". Additionally, this effort further suggested that C.H. Colley, (yet another Social Behaviorist writing before Mead)) was familiar with Einstein's QE and Nagarajuna philosophy having a profound effect on the concept of the "Looking Glass self" (LGS). The LGS suggested that the behavior of others is a mirror reflection of self ("what I am versus what I am seen as by others") (Gerardi, 2010). Finally, Cooley as a person of science simply could not explain the "looking Glass Self" based in "spooky Action at a Distance", rather the rational concept of social interaction (Nagarajuna's concept of the impact of Society found in Sunyata) affirms the social self.

\section{Conclusion}

Einstein in his 1905 Theory of Relativity explained that light has characteristics of both wave and particles. He also suggested that Quantum Theory could not be fully complete without first explaining what he called "Spooky Action at a Distance" (Quantum Entanglement). As we saw earlier, before QE was fully investigated it was believed that subatomic particles communicated to each other from far away at the speed of than light (hence the idea of "spooky" or irrational thought). However, after extensive study of this phenomenon (Q.E.), it became clear to Einstein that the photons become entangled at the same time from the same source. The two particles are linked, hence share the same existence. They do not communicate at the speed of light; rather they are identical particle (Musser, 2015). This effort suggested that this realization could have not been possible without first the affirmation of this state by society (Sunyata). Hence, once a phenomenon is noticed, (as in the case of QE, the "I" and "ME" and the "looking Glass Self") its' existence is real (can be proven scientifically), and not "Spooky Action at a Distance". Moreover, Nagarajuna Sunyata suggested that all "things" are "EMPTY". "Things" neither exist nor do not exist; neither affirmation nor negation. Energy is invisible, inaudible, and intangible. It is permanent and immutable. It has no beginning and no end; it remains changeless even while it takes various forms based in Society's recognition. The development of the two qualities of self (Mead) and the "Looking Glass Self" (Cooley) all could not have been possible without the affirmation of society, hence all "Share" the same existence, which became the foundation bases of the major theories of the American Social Behaviorist Movement in the 20th Century. Indeed, the 20th Century Social Behaviorist placed importance on the importance of social interaction in the development of the "Self". Indeed, this effort suggested that Mead and Cooley were scholarly followers of Nagarjuna's work which emphasized the importance of society's recognition of natural (Gerardi, 2016), and natural phe- 
nomenon (Kerzin, 2010). Equally as important was Einstein's work on Q.T. for it changed Wester Science, however if had not been Nagarjuna philosophy, the West may not have had the concept of Quantum Entanglement, "Social Self" and the "Looking Glass Self” (Gerardi, 2018).

\section{Conflicts of Interest}

The authors declare no conflicts of interest regarding the publication of this paper.

\section{References}

Bottott, J. (2019). Quantum Space. Oxford: Oxford University Press.

George, H. M. (1935). The Mind, Self and Society. Chicago, IL: University of Chicago.

Gerardi, S. (2010). A Brief Survey of the Sociological Imagination (3rd ed.). Dubuque, IA: Kendall/Hunt.

Gerardi, S. (2012). The Dialectical Relationship between Religion and the Ideology of Science. Sociology Mind, 2, 50-52.

Gerardi, S. (2016). Nagarjuna's Influence on the Major Theorist of the Frankfurt School. Global Journal of Human Social Science, 16, 15-16.

Gerardi, S. (2018). Quantum Superposition/Social Superposition and Classic Sociological Theory. Sociology Mind, 8, 21-24.

Kerzin, B. (2010). Nagarjuna's Wisdom. Rhinebeck, NY: Monkfish Book.

Kuttner, F., \& Bruce, R. (2011). Quantum Enigma: Physics Encounters Consciousness. Oxford: Oxford University Press.

Musser, G. (2015). Spooky Action at a Distance. New York: Scientific American, Farrar, Straus \& Giroux. 